\title{
LOS SEGUROS Y LA PROTECCIÓN DEL MEDIO AMBIENTE*
}

\section{INSURANCE AND ENVIRONMENTAL PROTECTION}

\author{
SERGIO GUIDO VILLEGAS ${ }^{* *}$
}

Fecha de recepción: 20 de febrero de 2017 Fecha de Aceptación: 2 de mayo de 2017 Disponible en linea: 30 de junio de 2017

\section{Para Citar este artículo/To cite this article}

Guido Villegas, Sergio, Los seguros y la protección del medio ambiente, 46 Rev.Ibero-Latinoam.Seguros, 89-108 (2017). https://doi.org/10.11144/ Javeriana.ris46.spma

doi:10.11144/Javeriana.ris46.spma

* Estudio doctrinal presentado en el XV Congreso del Comité Iberolatinoamericano de AIDA-CILA, Santa Cruz, Bolivia, Mayo 2017.

** Máster en Derecho por la Universidad Complutense de Madrid, Especialista en Derecho de Seguros. Socio de Dextra Law y Special Counsel de Batalla Salto Luna Abogados 


\section{RESUMEN}

El ámbito del seguro ha propuesto alternativas para abordar el daño ambiental, pero debemos cuestionarnos si son suficientes y adecuadas para enfrentar los retos y las complejidades de esa materia. En este sentido, se han analizado los seguros de daños ambientales y los seguros de responsabilidad civil por daños ambientales para evidenciar si estos son las figuras jurídicas idóneas o si por el contrario resultan insuficientes. Asimismo, se señalan algunos otros medios alternativos de dispersión de riesgo menos conocidos, pero cuyo radio de acción es más amplio que el del seguro y parecen una mejor herramienta para paliar las consecuencias del daño ambiental.

Palabras clave: Seguro; daño ambiental; responsabilidad civil; fondos de compensación. 


\begin{abstract}
Insurance alternatives have been proposed to compensate environmental damage, yet we must question whether they are sufficient and adequate to face the challenges and complexities of that matter. In this sense, environmental damage insurance and civil liability insurance for environmental damage have been briefly analyzed to show if these are the best legal solutions or if they are otherwise insufficient. This article also indicates other less known alternative means of risk dispersion, but whose range of action is broader than that of insurance and seem a better tool to repair the consecuencias of an environmental damage.
\end{abstract}

Keywords: Insurance, environmental damage, civil liability, compensation funds.

\title{
SUMARIO
}

1. INTRODUCCIÓN - 2. EL RIESGO COMO ELEMENTO ESENCIAL DEL SEGURO AMBIENTAL - 3. NOCIÓN DE CONTRATO DE SEGURO AMBIENTAL:A) Seguros de daños ambientales; B) Seguros de responsabilidad civil por daños al medio ambiente -4 . REFLEXIONES FINALES 


\section{INTRODUCCIÓN}

La protección del medio ambiente a través de la figura del seguro podría, en principio, pensarse contradictoria puesto que uno de los principios generales del Derecho Ambiental es el "principio de prevención"1.

En otras palabras, la defensa del medio ambiente desde la óptica del Derecho Ambiental se aborda, en primera instancia, mediante la prevención del daño y no a través de la reparación o compensación de éste, la cual podría producirse mediante la indemnización pecuniaria o en especie (in natura) del daño causado. La razón de lo anterior radica en el tipo de bien sobre el que recae la protección jurídica, el cual en la mayoría de los casos es de imposible o difícil reparación.

La normativa ambiental costarricense tímidamente ha empezado a utilizar mecanismos de dispersión de riesgos, para garantizar la viabilidad de proyectos con impacto potencial en el medio ambiente. Así puede analizarse entre otras normas las garantías de cumplimiento establecidas en el artículo 21 de la Ley Orgánica del Medio Ambiente, Ley № 7554, y el artículo 107 del Código de Minería, Ley $N^{\circ} 6797$; la garantía financiera a la que se refiere el artículo 45 de la Ley para la gestión integral de residuos, Ley $\mathrm{N}^{\circ} 8839$, las fianzas establecidas en los artículo 88 y 111 de la Ley de Aguas, Le, $N^{\circ} 276$ y las garantías de cumplimiento y participación que impone el artículo 88 del Reglamento general sobre los procedimientos de evaluación de impacto ambiental (EIA) Decreto Ejecutivo No. 31849-MINAE-S-MOPT-MAG-MEIC.

Este trabajo se centra en el análisis de los seguros ambientales, cuya regulación e implementación no ha sido desarrollada en Costa Rica. En los apartados siguientes se pretende evidenciar los elementos que distinguen este tipo de seguro con el fin de generar conciencia sobre la importancia de su implementación para la internalización de los costes ${ }^{2}$ de una determinada actividad.

1 Este principio lo recoge la normativa internacional desde Declaración de Estocolmo sobre el medio ambiente humano; Posteriormente fue incorporado en la Cumbre de las Naciones Unidas para el Medio Ambiente y el Desarrollo, celebrada en la ciudad de Río de Janeiro, Brasil, en junio de 1992 en el Principio 2.

2 Ver COASE, R. (1960), “The problem of social cost” Journal of Law and Economics, y CALABRESI, G. (1970). "Some thoughts on risk distribution and the law of torts" Yale Law Journal, 1961 y "The Costs of Accidents" . New Haven: Yale University Press. 


\section{EL RIESGO COMO ELEMENTO ESENCIAL DEL SEGURO AMBIENTAL}

La Ley Reguladora del Contrato de Seguros, Ley N $8956^{3}$, en su artículo 8 establece que el riesgo es un elemento esencial del contrato de seguro, y que su ausencia provoca la nulidad del contrato.

No obstante, dicho concepto debe diferenciarse del siniestro (daño) propiamente dicho. Según GARRIGUES el primero es un estado mientras que el segundo es la realización efectiva del riesgo. Lo primero es la posibilidad mientras que lo segundo es una realidad ${ }^{4}$.

En otras palabras, el riesgo de daño al medio ambiente es el hecho generador que provoca el nacimiento del seguro, entendido éste, no solo como instrumento para la indemnización de los efectos de una determinada acción, sino también como un instrumento para la internalización de los costes derivados de una actividad potencialmente nociva para el medio ambiente.

El concepto de medio ambiente ${ }^{5}$ ha sido definido mediante el artículo 1 de la Ley $\mathrm{N}^{\circ} 7554$, Ley Orgánica del Ambiente, que establece al final del según párrafo: "Se define como ambiente el sistema constituido por los diferentes elementos naturales que lo integran y sus interacciones e interrelaciones con el ser humano. Aunado a lo anterior, este concepto perfilado por la jurisprudencia, y ha sido concebido desde un sentido amplio. Así, en la Sentencia de la Corte Suprema de Justicia, Sala Constitucional de las 9:05 horas del 23 de diciembre del 2011 se indica:

"La Sala ha optado por una consideración abierta o macro del concepto ambiente y de la protección que se brinda al mismo, trascendiendo de

3 Artículo 8.- Elementos esenciales del contrato de seguro.

Son elementos esenciales del contrato de seguro:

a) El consentimiento de las partes

b) El interés asegurable presente o futuro

c) El riesgo asegurable

d) La prima del seguro o el procedimiento para determinarla

e) La obligación del asegurador.

Será absolutamente nulo el contrato de seguro que carezca de alguno de estos elementos esenciales

4 GARrigueS J. (1974), “Curso de Derecho Mercantil”, Tomo II, 6a Edición, Madrid, p. 248. Se define como la posibilidad de que por azar ocurra un hecho que produzca una necesidad patrimonial

5 Sentencia de la Sala Constitucional de las 9:05 del 23 de diciembre del 2011 .También se puede consultar sobre este concepto a MARTÍN MATEO, “Tratado de derecho ambiental, vol I, Madrid, p. 86. 
la protección básica o primaria del suelo, el aire, el agua, los recursos marinos y costeros, minerales, bosques, diversidad de flora y fauna, y paisaje, para considerar también elementos referentes a la economía, a la generación de divisas a través del turismo, la explotación agrícola y otros. Así mediante sentencia número 5893-095, de las nueve horas cuarenta y ocho minutos del 27 de octubre de 1993, la Sala estableció que: El Derecho Ambiental no debe asociarse sólo con la naturaleza, pues ésta es únicamente parte del ambiente. La política de protección a la naturaleza se vierte también sobre otros aspectos como la protección de la caza, de los bosques, de los parques naturales y de los recursos naturales. Se trata, entonces, de un concepto macro-ambiental, para no dejar conceptos importantes por fuera y así lograr unificar el conjunto jurídico que denominamos Derecho Ambiental".

De esta primera aproximación, se desprende que daño ambiental es el que afecta o lesiona el medio ambiente (como un bien jurídico de carácter difuso); pero lo es también aquel daño que vulnera derechos privados de índole patrimonial, moral o personal como consecuencia de la alteración del equilibrio ecológico. Se distinguen así dos tipos de daños ambientales; llamaremos al primero daño ecológico y al segundo daño ambiental tradicional, el cual es el que aquí nos ocupará.

Los daños ambientales comparten los elementos del daño de la doctrina clásica de la responsabilidad, y solo podrá ser indemnizado aquel que resulte personal, actual y cierto ${ }^{6}$. Sin embargo, posee características propias que dificultan la aplicación de la responsabilidad civil y con ello, la adecuada indemnización o reparación.

Así, debido a que el daño ambiental puede afectar intereses difusos, el carácter personal del daño se disipa, ya que las consecuencias nocivas las percibe una colectividad. De esta manera quien pretende reclamarpor la vía de la responsabilidad civil - una indemnización por el daño sufrido, debe probar que éste ha sido causado a bienes o derechos sobre los que ostente una titularidad jurídico-privada.

Por otro lado, dijimos que el daño debe ser actual, pero muchos de los daños ambientales son "daños sobrevenidos", es decir, se manifiestan con el transcurso del tiempo, como una consecuencia directa de daños

6 ÁlVAREZ LATA, N, (2003) "La responsabilidad civil por daños al medio ambiente", Tratado de Responsabilidad Civil, Fernando Reglero Campos y otros, $2^{\text {a }}$ Edición, Editorial Aranzadi, Navarra, p. 1706-1720. 
ambientales que ocurrieron con anterioridad ${ }^{7}$. Finalmente, la certeza del daño puede plantear problemas cuando el estado de la ciencia no sea lo suficientemente preciso para determinar la existencia del daño.

A las anteriores características, es necesario agregar las dificultades que plantean los daños ambientales en cuanto a la determinación del agente dañoso y la relación de causalidad entre la acción u omisión y el daño causado.

Uno de los presupuestos básicos para plantear las acciones de responsabilidad civil es la existencia de un sujeto que cause el daño. Si este no puede determinarse, dicha acción se ve frustrada por falta de legitimación pasiva. En los daños ambientales, resulta frecuente la indeterminación del sujeto causante del daño al medio ambiente, pero además la determinación de la relación de causalidad entre la conducta y el daño, en muchos daños ambientales encierra una gran dificultad ${ }^{8}$.

\section{NOCIÓN DEL CONTRATO DE SEGURO AMBIENTAL}

La Ley Reguladora del contrato de seguros, Ley $\mathrm{N}^{\circ} 8956$, estable una definición general de contrato de seguros ${ }^{9}$, que en este trabajo se toma como punto de partida para llegar a una aproximación de lo que debe entenderse por seguros ambientales.

El seguro ambiental comparte ciertos elementos básicos de la definición clásica del seguro: a) el interés asegurable, b) el riesgo, c) el pago de la prima y d) la indemnización del asegurador.

7 Sobre "daños sobrevenidos" ver la referencia que formula DE MIGUEL PERALES C. (1997), " $L a$ responsabilidad civil por daños al medio ambiente”, Editorial Civitas, Madrid, p p. 341.

8 En este mismo sentido puede consultarse a LOZANO CUTANDA B. (2005), "Derecho Ambiental Administrativo”, Editorial Dykinson, 5 Edición, Madrid, p. 253. También DE MIGUEL PERALES C. op. cit. p.p. 145 - 200, hace un interesante análisis sobre los problemas referidos a que reviste la relación de causalidad en la responsabilidad civil por daños al medio ambiente. DE ANGEL YAGÜEZ R. (1991), se refiere en este punto a los casos de la llamada "contaminación por sinergia", esto es, la que obedece no a una causa aislada, sino a la confluencia de varias, de orígenes diversos, "Comentario del Código Civil” T. II, p. 2047.

9 Artículo 3.- Contrato de seguros.- El contrato de seguros es aquel en que el asegurador se obliga, contra el pago de una prima y en el caso de que se produzca un evento cuyo riesgo es objeto de cobertura, a indemnizar el daño producido a la persona asegurada, o a satisfacer un capital, una renta $u$ otras prestaciones dentro de los límites y las condiciones convenidos. Las aseguradoras que operan en el mercado nacional podrán colocar, por sí o por medio de una de sus subsidiarias, contratos de seguros fuera del territorio nacional, ajustándose a los requerimientos legales de cada país en el que deseen operar. 
En virtud de lo anterior, el seguro ambiental se basa en el pago de una prima por el asegurado/tomador al asegurador, obligándose este último como contraprestación por dicha prima a indemnizar o reparar el daño ambiental sufrido por el asegurado, o bien el que éste haya causado.

La definición propuesta anteriormente abarca dos clases de seguros ambientales de los que haremos una breve referencia, las cuales entendemos son las categorías más difundidas de este tipo de seguro.

Para los fines de este artículo, para facilitar la exposición, se analizarán lo que llamaremos seguros de daños ambientales y seguros de responsabilidad civil por daños ambientales (aunque técnicamente este último también es un seguro de daños).

\section{A. Seguros de daños ambientales}

En esta categoría tendríamos los seguros de primera persona contra daños ambientales sufridos en la propia propiedad y el aseguramiento directo de daños ambientales (algunos tipos de seguros de cosechas (plagas), seguros de incendios), o bien seguros contra riesgos catastróficos y fenómenos naturales, tales como el granizo, las inundaciones o la sequía, entre otros.

En el seguro de primera persona la indemnización recae directamente en la víctima del daño tan pronto como el daño ocurra ${ }^{10}$. Por lo anterior, a simple vista puede comprenderse que el tema de fondo para el cobro de la indemnización - en este tipo de seguro - es un tema de causalidad del daño y no de culpabilidad. En otras palabras, quien pretenda el cobro de una determinada indemnización por un seguro ambiental de primera persona, tendrá que demostrar el daño sufrido y el nexo de causalidad entre el daño y la conducta del agente causante del daño, no así su culpabilidad en la conducta o acción/omisión dañosa.

En un esquema puro de seguro de primera persona, la potencial víctima del daño busca cobertura del asegurador por los daños que ella

10 FAURE M. (2001) en "Environmental Damage Insurance in Theory and Practice”, METRO, London, p. 16. 
misma pueda sufrir, por lo que en principio podría argumentarse que este tipo de seguro no tendría una gran aplicación en el ámbito ambiental. No obstante, la aplicación de un sistema de aseguramiento directo - similar al seguro de primera persona - sí puede proporcionar alternativas interesantes en este campo.

El aseguramiento directo no es desconocido en Costa Rica, al contrario, hemos convivido con dicho esquema desde hace más de tres décadas con la reforma que introdujo en el Código de Trabajo, la Ley de Riesgos del Trabajo, Ley No 6727 de fecha 9 de marzo de 1982.

En la práctica un aseguramiento directo de los riesgos ambientales, supondría que una determinada empresa podría asegurar a los predios aledaños y/o a sus dueños de posibles daños derivados de contaminación por la actividad económica que desarrolle. Como indica FAURE, bajo el esquema de aseguramiento directo, el tomador del seguro no es la víctima sino el potencial causante del daño. Esto no es, sin embargo, un seguro de responsabilidad civil, puesto que el riesgo cubierto no es la responsabilidad en la que incurra el tomador, sino los daños sufridos por la víctima ${ }^{11}$.

Huelga decir que dichos daños no son todos ni cualesquiera que haya sufrido la víctima, sino que el asegurador indemnizará aquellos que haya previsto y especificado el tomador y los cuales hayan sido aceptados por él.

A pesar de lo señalado, debe concluirse que la aplicación de este tipo de seguros es limitada en el tanto se pretenda asegurar los daños sufridos en bienes propios, puesto que en la mayoría de los bienes ambientales no recae una titularidad jurídico-privada, sino que por el contrario son bienes colectivos (ríos, mares, bosques, aire, entre otros). Evidentemente esta ausencia de derechos de propiedad en estos bienes hace inviable, en algunos casos, la configuración del seguro puesto que faltaría uno de los elementos esenciales, el interés asegurable. La salvedad podría hacerse en plantaciones o bosques privados y también en el suelo, sobre los cuales sí existen derechos de propiedad privada.

11 FAURE, M. (2001) Environmental Damage Insurance in Theory and Practice”, op. cit. p. 19. 
En otras palabras, la existencia del interés asegurable es un presupuesto para la validez del contrato ${ }^{12}$, y la ausencia de este elemento provoca la nulidad del contrato de seguro $^{13}$. En igual sentido el artículo 8 de la Ley Reguladora del Contrato de Seguro, Ley N ${ }^{\circ} 8956$, establece como uno de los elementos esenciales del contrato de seguro el interés asegurable presente o futuro, y sanciona la ausencia de interés con nulidad absoluta del contrato ${ }^{14}$.

\section{B. Seguros de responsabilidad civil por daños al medio ambiente}

El desarrollo del seguro de responsabilidad civil puede ubicarse en la sociedad industrial con la aparición de los riesgos del desarrollo ${ }^{15}$. Este tipo de seguro se caracteriza por ser un seguro de tercera persona, en el tanto es el tercero que sufre el daño, es el que recibirá la indemnización proveniente del seguro ${ }^{16}$. El artículo $84^{17}$ de la Ley Reguladora del Contrato de Seguros, Ley $N^{\circ}$ 8956, regula la concepción de este seguro en nuestro ordenamiento, imponiendo la obligación al asegurador de responder de las indemnizaciones que deba pagar la persona asegurada a favor de terceros, por daños causados a la propiedad, por lesión o muerte. Lo

12 En este sentido STIGLITZ 1956: “Derecho de seguros”, Tomo I, Buenos Aires, 1997, p.p. 252 y ss. y DONATI: “Trattato del Diritto delle Assicurazioni Private”, Vol. II, Milán, p. 205.

13 Ver en igual sentido SÁNCHEZ CALERO, F. (2005), "Ley de Contrato de Seguro. Comentarios a la

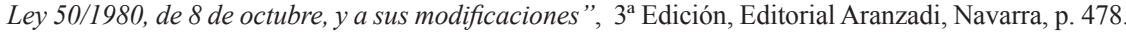

14 Artículo 8.- Elementos esenciales del contrato de seguro.

Son elementos esenciales del contrato de seguro:

a) El consentimiento de las partes

b) El interés asegurable presente o futuro

c) El riesgo asegurable

d) La prima del seguro o el procedimiento para determinarla

e) La obligación del asegurador.

Será absolutamente nulo el contrato de seguro que carezca de alguno de estos elementos esenciales.

15 Ver ese sentido LÓPEZ-COBO, C. (1988) "El seguro de responsabilidad civil. Fundamento y modalidades”, Nacional de Reaseguros SA, Madrid, p. 26.; CALZADA CONDE, M. A., (1983) “El Seguro voluntario de responsabilidad civil”, Editorial Montecorvo, Madrid, p. 30.

16 Ver en este sentido SÁNCHEZ CALERO, F. op. cit. p. 1132.

17 Artículo 83.- Objeto del contrato. El seguro de responsabilidad civil impone al asegurador la obligación de responder de las indemnizaciones que deba pagar la persona asegurada a favor de terceros, por daños causados a la propiedad, por lesión o muerte. Son asegurables tanto la responsabilidad contractual como la extracontractual, no así la responsabilidad derivada de dolo o culpa grave de la persona asegurada o de las personas por las que este responda civilmente. El seguro de responsabilidad civil no cubre multas, penas u otras sanciones similares que se impongan en contra de la persona asegurada. 
anterior, presupone la existencia de cuatro elementos: a) el nacimiento de una deuda de responsabilidad; b) que de dicha deuda deba responder el asegurado; c) que la deuda de responsabilidad provenga de un hecho dañoso que dé lugar a la indemnización de daños y perjuicios y d) que el hecho dañoso esté previsto en el contrato o, bien, que su cobertura no esté excluida.

Como indica ZUBIRI ${ }^{18}$, desde el punto de vista de los daños causados al medio ambiente, hemos de destacar que el riesgo asegurado será la posibilidad de que ocurra un daño al medio ambiente como consecuencia de la acción u omisión del empresario en su actividad y por el que se le reclame una indemnización. Por esta razón, puede decirse que tiene un radio de acción más amplio que el seguro de daños ambientales analizado anteriormente, puesto que abarca todos aquellos daños que un agente contaminante puede causar en bienes ambientales, sean estos de naturaleza pública o privada.

Si bien la aplicación de este tipo de seguro está bastante extendida, no por eso está exento de problemas. ALVAREZ LATA señala que el tradicional seguro de responsabilidad civil se ha revelado como un instrumento problemático. Se apuntan varias causas: la falta de aleatoriedad del riesgo, porque, en muchas ocasiones se trataría de daños resultantes de emisiones autorizadas o de conductas poco escrupulosas que determinarían la causación voluntaria del daño, al margen de la denominada "carga antigua de siniestro", que implica la existencia de un daño latente que aún no se ha manifestado pero que ya concurre en el momento de la suscripción del seguro - todas las circunstancias implican la pérdida del aleas típica del contrato de seguro -; el riesgo incalculable para las aseguradoras, ya que aun adoptando las técnicas de producción más limpias y los estándares más rigurosos no se eliminaría el acontecimiento dañoso y, por tanto, el pago de indemnizaciones; la dificultad para calcular la tasa de siniestralidad (y, por ende, las consecuencias financieras del seguro y la prima de asegurado), debido sobre todo a factores derivados del ámbito temporal de los daños asegurables que complican esta tarea de evaluación (contaminación histórica, carga antigua, etc.) y de lo que se conoce

18 ZUBIRI DE SALINAS, M. (2005) "El seguro de Responsabilidad Civil por daños al medio ambiente”, Editorial Aranzadi, Navarra, p. 62. 
como estado del arte; o la acumulación, en el caso de la contaminación crónica, que impide la atribución de responsabilidad individualizada, lo que supone un escollo importante para las aseguradoras ${ }^{19}$.

Otros problemas que enfrenta el seguro de responsabilidad civil por daño ambiental son la capacidad del asegurador para medir la magnitud del daño y la selección adversa, la cual debe resolverse por una adecuada diferenciación del riesgo.

Desde el punto de vista de la víctima, el seguro de responsabilidad civil presenta vacíos e interrogantes importantes, aún pendientes de resolver. Tal es el caso de la problemática que encierra la demostración de la culpabilidad o negligencia en la acción u omisión causante del daño. No basta con que exista una tendencia hacia la objetivación de la responsabilidad civil en materia ambiental, si el contrato que cubre la responsabilidad del agente dañoso no se desvincula del sistema de causalidad, ya que al atribuirse una determinada acción al asegurado, la víctima solamente obtendrá cobertura del seguro en el tanto pruebe su negligencia. En caso contrario, la aplicación del sistema de la responsabilidad civil objetiva le permitiría la reclamación contra el patrimonio de dicho asegurado, pero no la indemnización proveniente de la cobertura del seguro.

A estas reflexiones debe añadirse, la complejidad que entraña en algunos casos la aplicación de las cláusulas de limitación temporal del seguro $^{20}$.

A la luz de lo anterior, piénsese en la dificultad que entrañaría la indemnización de un daño en aplicación de un seguro de responsabilidad civil en casos de contaminación por acumulación de vertidos, en donde haya varias empresas contaminantes, y en donde parte de la contamina-

19 ALVAREZ LATA, N. op. cit., p. p. 123 y 124.

20 Artículo 15.- Período de cobertura.- Los contratos de seguros podrán regular el período de cobertura del seguro bajo la base de la ocurrencia del siniestro o de la presentación del reclamo. En el primer caso, el seguro cubrirá únicamente reclamos por siniestros acaecidos durante la vigencia de la póliza, aun si el reclamo se presenta después de vencida esta vigencia y de conformidad con lo convenido por las partes. En el segundo caso, el seguro solo cubrirá los reclamos que presente la persona asegurada al asegurador dentro de la vigencia de la póliza, siempre y cuando el siniestro haya acaecido durante la vigencia del contrato o después de la fecha retroactiva si esta se hubiera pactado por las partes. La póliza deberá indicar cuál período de cobertura aplica al caso respectivo. En caso de duda se aplicará el período de cobertura que mejor convenga a la persona asegurada. 
ción que hayan generado dichas empresas se hayan producido durante la vigencia de la póliza y otras no.

Estas y otras dudas son los problemas diarios que enfrenta la aplicación de este tipo de seguro y es por ello que muchas aseguradoras han optado por eliminar su comercialización o, bien, por reasegurar en buena parte los riesgos aceptados con el fin de dispersar el riesgo.

\section{REFLEXIONES FINALES}

El análisis económico del derecho ha aportado algunas ideas y reflexiones que son de plena aplicación en este campo y que, mediante la implementación de un adecuado esquema de seguros y una correcta asignación de responsabilidad a los generadores potenciales de los daños ambientales, puede resultar en una prevención indirecta nada despreciable para el medio ambiente. Tal y como afirma POSNER, la compensación del daño no debe ser el único fin del sistema de responsabilidad, sino que su función económica debe radicar en la prevención de accidentes económicamente ineficientes ${ }^{21}$.

Dentro del Derecho Privado, el mecanismo de la Responsabilidad Civil cumple una función de protección de las víctimas de daños ambientales tradicionales (sufridos en bienes y derechos de titularidad jurídicoprivada). Esta función protectora no se agota en esta rama del Derecho, sino que se complementa con otras como el Derecho Administrativo y Penal. No obstante, la forma más adecuada de abordar la protección del medio ambiente no es de forma sectorial, es decir, considerando a cada una de las ramas del Derecho por separado, sino que debe abordarse de una manera integral. La razón de esta afirmación radica en la complejidad del daño ambiental, ya que éste puede vulnerar tanto bienes colectivos como individuales. Por esta razón entendemos que el seguro, en relación con el instituto de la responsabilidad civil, cumple un papel importante en la protección del medio ambiente.

Tal y como se explicó anteriormente, existen diversos tipos de seguros ambientales que actualmente se utilizan para paliar las consecuencias económicas de los daños ambientales. Algunos de ellos incluso incorporan un elemento

21 Según POSNER R. (2007) “Economic Analysis of Law”, 7ª Edición, Wolters Kluwer, New York, p. 200. 
que, a mi juicio, es completamente necesario por razón de la materia, cual es la reparación in natura del daño en lugar de la indemnización pecuniaria de los daños y perjuicios. Esto quiere decir que, producido el daño y probado quién es el responsable, el Asegurador se encargaría de devolver las cosas a su estado original, y en caso de no ser posible pagaría una determinada cantidad de dinero a las víctimas. No obstante, desde este momento debe indicarse que no en todos los casos será posible devolver las cosas a su estado inicial, por lo que a nuestro entender el proceso de aplicación de los seguros ambientales debe siempre complementarse con un adecuado plan de mitigación y análisis de riesgos con el fin de determinar la viabilidad del aseguramiento.

La otra opción que han aplicado algunos países como España, con el llamado Pool Español de riesgos medioambientales, o Estados Unidos con el llamado Comprehensive Environmental Response Compensation and Liability Act (CERCLA), es un sistema en el que un grupo de empresas cuyas actividades son susceptibles de causar daños ambientales contribuyen a un fondo común destinado a atender los daños colectivos que cause cualesquiera de ellas, con la particularidad de que estos fondos responden de forma objetiva a los daños que reclamen las víctimas. Es decir, quien sufre el daño no debe demostrar quién tuvo la culpa del daño, sino que solo debe probar que ha sufrido un daño por una determinada actividad amparada por el fondo, $\mathrm{y}$ este último pagará y luego intentará resolver quién fue el causante del daño.

En el ámbito internacional, destaca el denominado "Superfund" norteamericano, creado por la Comprehensive Environmental Response and Liability Act, de 1980, con el objeto de hacer frente a supuestos de emergencias y limpieza de suelos contaminados originados por el depósito incontrolado de residuos tóxicos o peligrosos. El fondo se financia con las aportaciones obligatorias de las industrias potencialmente contaminantes y su objetivo es la limpieza de los suelos. Se intenta, en primer lugar, hacer responsable del coste de la limpieza a su causante, siguiendo el modelo de responsabilidad civil objetiva imperante en Estados Unidos, pero cuando esto no resulta posible, porque el responsable no se puede identificar o es insolvente, se complementa el sistema con la aplicación de los fondos para la restauración de los suelos dañados ${ }^{22}$.

22 LOZANO CUTANDA B., (2005) "Derecho Ambiental Administrativo", Editorial Dykinson, 5 Edición, Madrid, p. 253. 
Como bien apunta DE MIGUEL PERALES, en cierto sentido es una especie de seguro obligatorio, aunque sólo en apariencia, ya que otro de los objetivos que cualquier fondo debe perseguir recuperar del verdadero responsable los costes de la reparación del daño, ya que así, a la par que se garantiza la viabilidad práctica del fondo, se consigue una esencial función preventiva, al ser los contaminadores conscientes de que por el hecho de pagar una relativamente pequeña cantidad periódica, no se ven libres de soportar la totalidad de su responsabilidad por los daños que causen ${ }^{23}$.

Las particularidades del daño ambiental hacen que en algunos casos el sistema de la responsabilidad civil y, consecuentemente el seguro, sean inoperantes, ya sea porque la demostración de la culpabilidad resulta imposible, o bien, porque al existir un problema de contaminación acumulada resulta compleja la determinación del agente dañoso. En estos casos es cuando surge la utilidad de los fondos ambientales ya que la idea que subyace en este sistema es que los daños sufridos no queden sin reparación. En nuestro medio, dicho sistema tendría plena acogida al amparo del artículo 41 de la Constitución Política que establece:

Artículo 41.- Ocurriendo a las leyes, todos han de encontrar reparación para las injurias o daños que hayan recibido en su persona, propiedad o intereses morales. Debe hacérseles justicia pronta, cumplida, sin denegación y en estricta conformidad con las leyes.

Como indica DESPAX, la existencia de mecanismos de financiación colectiva permite no sólo acelerar los procesos de reparación, sino también prevenir aquellos casos de insolvencia del responsable por razón de la importancia de los daños ocasionados por la contaminación, o en aquellos otros en los que el sujeto agente contaminador no está identificado, e incluso, cuando la contaminación tiene su origen en un suceso exonerador de responsabilidad, tales como unas condiciones climatológicas excepcionales o un terremoto ${ }^{24}$.

23 DE MIGUEL PERALES C. (1997) "La responsabilidad civil por daños al medio ambiente”, Editorial Civitas, Madrid, p. 260.

DESPAX, (1980) Droit de l'environment, París, p. 800. 
Debe hacerse especial mención de dos puntos que, en mi criterio, son básicos del sistema de fondos de compensación. El primero de ellos es el tema de la subsidiaridad del fondo. La constitución de un fondo de compensación puede contemplar o no la obligación para el tercero perjudicado de accionar en primera instancia contra el presunto causante del daño, y solamente cuando dicha reclamación se vea frustrada podrá entonces reclamar contra el fondo de compensación.

Dicho sistema, a pesar de su validez, presenta desde mi punto de vista serios inconvenientes. Por un lado, debe señalarse el problema de la falta de celeridad para la reparación del daño o la adopción de medidas cautelares que prevengan el daño continuado. La saturación que atraviesan los tribunales de justicia impiden en la mayoría de los casos, que un tema de esta naturaleza sea resuelto en un plazo corto, por lo que el perjudicado deberá esperar en ocasiones varios años para obtener una resolución judicial. Por otro lado, no existen garantías para el perjudicado de obtener una sentencia favorable, por lo que podría verse frustrada una posible acción de regreso por parte del fondo de compensación como entidad jurídica contra el presunto causante del daño por un tema de cosa juzgada material. Asimismo, la subsidiaridad en la utilización de los fondos de compensación podría reducir tanto su aplicación que, como bien indica DE MIGUEL PERALES, cabría entonces preguntarse si merece la pena tener un tal fondo (con toda la estructura que debe mantenerse, recursos financieros, etc.) si sólo va a ser utilizado en contadas ocasiones, ya que normalmente, o el perjudicado ha obtenido reparación a través del proceso, en cuyo caso no acudirá ya al fondo, o no ha obtenido una tal reparación, en cuyo caso sólo muy pocas veces podrá entonces darse el acceso al fondo (por ejemplo, porque se haga una prueba más flexible del nexo causal $)^{25}$.

El otro punto que debe mencionarse es el derecho de subrogación que surge para el fondo como entidad jurídica para reclamar los daños y perjuicios resarcidos contra el causante del daño. Debe hacerse énfasis en que este derecho en el ámbito ambiental es esencial, puesto que a través del ejercicio del derecho de subrogación se da cumplimiento no solo al "principio de quien contamina paga", sino que de forma in-

DE MIGUEL PERALES, C. op. cit., p.p. 274 y 275. 
directa se desincentiva el desarrollo de actividades que no cuenten con el respectivo seguro ambiental o bien, que no contemplen dentro de sus costos de operación las posibles contingencias de su actividad. Para la materialización de este derecho, una vez que el perjudicado reciba la correspondiente reparación del daño, deberá ceder sus derechos al fondo para que este pueda entablar las acciones legales correspondientes.

No desconocemos las críticas o desventajas que se han señalado a la aplicación de los fondos de compensación; sin embargo, entendemos que en cualquier caso las deficiencias que se apuntan son aspectos que deben mejorarse, sin que ello sea suficiente para descartar su aplicación.

En aras de hacer una síntesis de las bondades y desventajas señaladas se resume en el siguiente cuadro los argumentos en pro y en contra de los fondos de compensación.

\begin{tabular}{|l|l|}
\hline \multicolumn{1}{|c|}{ Ventajas } & \multicolumn{1}{c|}{ Desventajas } \\
\hline $\begin{array}{l}\text { No es necesario identificar al agente } \\
\text { dañoso }\end{array}$ & $\begin{array}{l}\text { Conduce a la socialización del riesgo in- } \\
\text { deseable }\end{array}$ \\
\hline $\begin{array}{l}\text { Puede repararse aun en supuestos de caso } \\
\text { fortuito o fuerza mayor }\end{array}$ & $\begin{array}{l}\text { Aumento de los precios de los productos } \\
\text { fabricados por el colectivo que nutre el } \\
\text { fondo de compensación }\end{array}$ \\
\hline $\begin{array}{l}\text { La prueba del nexo de causalidad del daño } \\
\text { es menos rígida }\end{array}$ & $\begin{array}{l}\text { Puede conllevar la disminución de los es- } \\
\text { tándares de diligencia con la que actúan } \\
\text { las empresas, ya que éstas se atendrían } \\
\text { a la existencia del fondo en perjuicio de } \\
\text { ciertos controles sobre su actividad }\end{array}$ \\
\hline Celeridad en la reparación & Mayor burocracia \\
\hline $\begin{array}{l}\text { El derecho de subrogación que nace de } \\
\text { la reparación del daño, conlleva una } \\
\text { finalidad preventiva del daño ya que } \\
\text { siempre se accionará contra los agentes } \\
\text { contaminantes }\end{array}$ & $\begin{array}{l}\text { En casos en los que se prevea la subsidiar- } \\
\text { idad del fondo, el derecho de subrogación } \\
\text { puede verse afectado por los efectos de la } \\
\text { cosa juzgada material }\end{array}$ \\
\hline $\begin{array}{l}\text { Fomenta la internalización de costes de- } \\
\text { rivados de las actividades }\end{array}$ & \\
\hline
\end{tabular}

Determinar qué sistema es mejor para Costa Rica -si el sistema basado en seguros ambientales o la aplicación de un sistema de fondos de compensación- o bien, si debe imperar un sistema mixto no es cosa 
sencilla. En Europa el debate que suscitó la implantación de un sistema de seguro ambiental obligatorio puede comprobarse a través de distintos documentos que antecedieron a la promulgación de la Directiva 2004/35 CE sobre responsabilidad medioambiental en relación con la prevención y reparación de daños medioambientales. Tal es el caso de la Comunicación de la Comisión al Consejo y al Parlamento Europeo y al Comité Económico y Social de 14 de mayo de $1993^{26}$.

En última instancia, pesaron las dudas que existieron y se expusieron en el Libro Blanco de responsabilidad ambiental del 2000 y se abandonó la idea del seguro obligatorio. Por esta razón y como bien indica $\mathrm{KOCH}$, la Directiva ha planteado la posibilidad de que se establezcan garantías financieras, dejando libertad a los Estados Miembros para que las establezcan o no. A manera de ejemplo, el legislador español ha preferido preverlas: los operadores de actividades enunciadas en el anexo III $^{27}$ y que pudieran ocasionar daños cuya reparación se evalúe por una cantidad superior a 300.000 euros, están obligados a suscribir una garantía financiera que puede consistir en un seguro, aval de una entidad financiera o reserva técnica, si bien pueden figurar como sujetos garantizados adicionales los subcontratistas y los profesionales que colaboren con estos operadores ${ }^{28}$.

$26 \operatorname{COM}(93) 47$ final:

2.1.11: El problema del aseguramiento.

Cuando se debate el tema de la responsabilidad civil se plantea el problema del aseguramiento, puesto que los seguros constituyen un medio de controlar el riesgo de pérdidas económicas.

Los seguros son un importante mecanismo de indemnización en los casos de daños por accidentes si los costes de restauración están cubiertos por una póliza de seguros. Si el que concede un seguro lo vincula a la calidad de gestión de riesgos de la empresa, éste tendrá un efecto disuasorio y fomentará una prevención de accidentes más adecuada y otros tipos de controles ecológicos de la actividad económica.

Las incertidumbres que dificultan la aplicación de la responsabilidad civil al daño ecológico plantean problemas también por lo que se refiere a los seguros. Las compañías de seguros tienen reparos en cubrir ciertas actividades si no se sabe qué tipos de daños pueden producirse y qué probabilidades hay de que ocurran, o si se dan pérdidas imprevistas que agostan la reserva de dinero. El régimen de responsabilidad civil instaurado, la ausencia de límites para la responsabilidad o la cobertura de riesgos especiales como la contaminación gradual, son elementos que dificultan a los aseguradores la labor de determinar hasta qué punto esos riesgos, ya de por sí bastantes complejos, son asegurables, y, llegado el caso, la de especificar el nivel de su compromiso. Debido a estas circunstancias se ven obligados, a veces, a aumentar las primas o a retirarse del mercado de los seguros de responsabilidad en materia de medio ambiente.

27 Se refiere a actividades potencialmente contaminantes sujetas a autorización administrativa.

28 KOCH, M., (2007) "Quien contamina no siempre paga. Análisis de las obligaciones y potestades de los sujetos contemplados en el Proyecto de Ley de Responsabilidad Medioambiental", Revista Ecosostenible, $\mathrm{N}^{\circ} 30$ - 31, Agosto - Septiembre, Madrid, p. 9. 
En cualquier caso, la importancia de este tipo de figuras, tanto del seguro como de los fondos de compensación, reside en la dispersión del riesgo a través de una prima o cuota que, por un lado permite la viabilidad económica del proyecto o actividad $\mathrm{y}$, por otro, garantiza a un colectivo la reparación de los daños potenciales que dicho proyecto o actividad puedan causar.

De optarse por incorporar un sistema de seguros ambientales, debe tenerse en consideración que si bien la tendencia moderna es hacia la objetivación de la responsabilidad ambiental, el seguro de responsabilidad civil ambiental incorpora el elemento de la culpabilidad, por lo que su aplicación podría implicar un retroceso en dicho campo. Por esta razón, los seguros de daños ambientales se vislumbran como un mecanismo más acorde a dicha tendencia doctrinal, aunque su aplicación es, como se analizó, más limitada que en el seguro de responsabilidad civil, por lo que la utilización de este último, pienso que no puede desecharse en su totalidad.

En virtud de lo anterior, me parece importante reflexionar acerca de la oportunidad de desarrollo que presenta para este país la implantación de un sistema que contemple un fondo de compensación. No obstante, su implementación considero en modo alguno puede desconocer la aplicación de los principios que rigen el Derecho Ambiental. Por ello, ante actividades que presenten un riesgo por el estado de la ciencia o bien porque la magnitud del daño sea totalmente desproporcionada con el beneficio a obtener, aún ante la presencia de un fondo de compensación, deberá imperar la aplicación del principio de precaución.

\section{BIBLIOGRAFÍA}

ÁLVAREZ LATA, N, "La responsabilidad civil por daños al medio ambiente", Tratado de Responsabilidad Civil, Fernando Reglero Campos y otros, $2^{\mathrm{a}}$ Edición, Editorial Aranzadi, Navarra, 2003.

CALABRESI, G. Some thoughts on risk distribution and the law of torts, Yale Law Journal, 1961 y The Costs of Accidents, New Haven: Yale University Press, 1970.

CALZADA CONDE, M. A., El Seguro voluntario de responsabilidad civil, Editorial Montecorvo, Madrid, 1983. 
COASE, R. The problem of social cost, Journal of Law and Economics, 1960.

DE ANGEL YAGÜEZ R. Comentario del Código Civil, T. II, 1991, p. 2047

DE MIGUEL PERALES, C. La responsabilidad civil por daños al medio ambiente, Editorial Civitas, Madrid, 1997.

DESPAX, Droit de l'environment, París, 1980.

DONATI: Trattato del Diritto delle Assicurazioni Private, Vol. II, Milán, 1956, p. 205.

FURE M. Environmental Damage Insurance in Theory and Practice, METRO, London, 2001.

GARRIGUES J. Curso de Derecho Mercantil, Tomo II, 6ª Edición, Madrid, 1974.

HEBRERO ÁLVAREZ J.I. "El aseguramiento de la responsabilidad civil por daños al medio ambiente”, Editorial Dykinson, Madrid, 2002.

KOCH, M., "Quien contamina no siempre paga. Análisis de las obligaciones y potestades de los sujetos contemplados en el Proyecto de Ley de Responsabilidad Medioambiental”, Revista Ecosostenible, N³0 - 31, Agosto - Septiembre, Madrid, 2007.

LÓPEZ-COBO, C., El seguro de responsabilidad civil. Fundamento y modalidades, Nacional de Reaseguros SA, Madrid, 1988.

LOZANO CUTANDA B., “Derecho Ambiental Administrativo”, Editorial Dykinson, $5^{\mathrm{a}}$ Edición, Madrid, 2005.

POSNER R. Economic Analysis of Law, 7 Edición, Wolters Kluwer, New York, 2007.

SÁNCHEZ CALERO, F. "Ley de Contrato de Seguro. Comentarios a la Ley 50/1980,

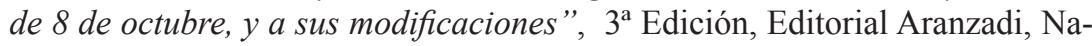
varra, 2005.

STIGLITZ, R. Derecho de seguros, Tomo I, Buenos Aires, 1997.

ZUBIRI DE SALINAS, M. El seguro de Responsabilidad Civil por daños al medio ambiente, Editorial Aranzadi, Navarra, 2005. 